\title{
Antifatigue Functions and Mechanisms of Edible and Medicinal Mushrooms
}

\author{
Ping Geng, ${ }^{1}$ Ka-Chai Siu, ${ }^{1}$ Zhaomei Wang, ${ }^{2}$ and Jian-Yong Wu ${ }^{1}$ \\ ${ }^{1}$ Department of Applied Biology \& Chemical Technology, State Key Laboratory of Chinese Medicine and \\ Molecular Pharmacology in Shenzhen, The Hong Kong Polytechnic University, Hung Hom, Kowloon, Hong Kong \\ ${ }^{2}$ School of Food Science \& Engineering, South China University of Technology, Guangzhou 510640, China \\ Correspondence should be addressed to Jian-Yong Wu; jian-yong.wu@polyu.edu.hk
}

Received 26 May 2017; Accepted 16 July 2017; Published 14 August 2017

Academic Editor: Yan Li

Copyright (C) 2017 Ping Geng et al. This is an open access article distributed under the Creative Commons Attribution License, which permits unrestricted use, distribution, and reproduction in any medium, provided the original work is properly cited.

Fatigue is the symptom of tiredness caused by physical and/or psychological stresses. As fatigue is becoming a serious problem in the modern society affecting human health, work efficiency, and quality of life, effective antifatigue remedies other than pharmacological drugs or therapies are highly needed. Mushrooms have been widely used as health foods, because of their various bioactive constituents such as polysaccharides, proteins, vitamins, minerals, and dietary fiber. This paper reviews the major findings from previous studies on the antifatigue effects, the active components of mushrooms, and the possible mechanisms. Many studies have demonstrated the antifatigue effects of edible and medicinal mushrooms. These mushrooms probably mitigate human fatigue through effects on the functional systems, including the muscular, cardiovascular, hormone, and immune system. The bioactive constituents that contribute to the antifatigue effects of mushrooms may include polysaccharides, peptides, nucleosides, phenolic compounds, and triterpenoids. Further research is still needed to identify the active ingredients and to investigate their mechanism of action on the antifatigue effects. Since most previous studies have been carried out in animal models, more human trials should be performed to verify the antifatigue function of edible and medicinal mushrooms.

\section{Introduction}

Fatigue is the physical or mental exhaustion caused by overwork, exercise, and lack of sleep. It can also be a symptom resulting from medicine, illness, anxiety, or depression. Fatigue affects more than $20 \%$ of people worldwide, which is usually associated with physical and/or psychological (mental) weakness [1]. For physical weakness, the individuals engaged in vigorous activities or laborious jobs may experience reduced efficiency and capacity for work. For psychological weakness, people with depression or sleep disorders may have the sense of weariness, exhaustion, and lack of motivation [2]. As fatigue can be misunderstood as laziness or lethargy, some people may not recognize it as a serious problem to seek proper treatment. The stimulants such as coffee, energy drinks, and even caffeine or ephedrine supplements taken by many people can only provide a temporary relief and even create health problems in the long run. Therefore, it is imperative to resolve fatigue through fundamental and constructive measures for repairing the dysfunction of the responsible body systems [3].

There is a long history for the medicinal use of mushrooms or their active components. Many research studies have demonstrated the various health benefits of edible and medicinal mushrooms such as antioxidant, anticancer, prebiotic, immunomodulating, anti-inflammatory, cardiovascular, antimicrobial, and antidiabetic activities [4-8]. Some mushrooms have also been shown to provide antifatigue functions by balancing various biological systems and helping to maintain the basic harmonious pattern of body. Meanwhile, previous studies have identified the major active constituents responsible for the biological effects of edible and medicinal mushrooms with polysaccharides being the most common and abundant $[9,10]$. Other bioactive compounds found in the mushrooms include peptides [11] and various organic molecules such as triterpenoids [12], nucleosides [13], phenolics, and flavonoids [14]. 
This review aims to summarize the recent studies on the antifatigue effect of edible and medicinal mushrooms. The physiological basis of fatigue is introduced with respect to the exhaustion theory, the radical theory, the clogging theory, and the hemoglobin theory. The antifatigue mechanism of edible and medicinal mushrooms is illustrated from several aspects including muscular function, antioxidant effect, cardiovascular function, immunomodulation, hormone regulation, hepatic function, and blood glucose regulation. The bioactive constituents responsible for the antifatigue functions are summarized.

\section{Physiological Basis of Fatigue}

Fatigue in medical term can be classified into chronic fatigue syndrome (CFS), central fatigue, and peripheral fatigue. CFS is a kind of neurological illness, which may be caused by abnormal function of immune system and neuroendocrine system, infections, or nutritional deficiency [15]. Patients suffering from CFS are in a serious medical condition and not easily recovered by rest. Central fatigue is associated with changes in the synaptic concentration of neurotransmitters, primarily serotonin, within the central nervous system (including the brain and spinal cord) [16]. For healthy individuals, central fatigue can occur after prolonged exercise and exerts a protective effect reducing muscle contraction to lower oxygen tension in brain and helps to balance various organs for normal functioning [17]. It is not directly linked with the level of physical exercise and thus cannot be explained by factors affecting muscle function. Peripheral fatigue mainly refers to physical fatigue, corresponding to "an inability to continue exercise at the same intensity with a resultant deterioration in performance" [18]. There are several theories explaining the physiological basis of peripheral fatigue, including the exhaustion theory, the radical theory, the clogging theory, and the hemoglobin theory.

Exhaustion theory suggests that fatigue results from exhaustion of liver and muscle glycogen reserves and significant decrease of blood glucose concentration [19]. Glucose is the primary source of energy for body cells, which is oxidized to generate ATP during cell respiration. The glucose not used as fuel will immediately travel to and be stored in liver or skeletal muscles in the form of glycogen or stored as fat in the adipose tissue. The stored glycogen in liver can convert back to glucose which will be released into bloodstream when blood glucose level drops. Under prolonged work or exercise, the glucose derived from stored muscle and liver glycogen will be insufficient, requiring additional energy produced from the oxidation of fat. However, the process of fat oxidation is difficult to supply high level of energy. People will experience fatigue when the glycogen stored in muscles and liver is depleted [20].

Radical theory indicates that free radicals such as hydroxyl and superoxide anion radicals will accumulate in the body after intense physical load and put the body in a state of oxidative stress because of imbalance between the body's oxidation system and antioxidation system. These free radicals, referred to as reactive oxygen species (ROS), will disturb the normal redox state in the cells, resulting in damage of cell components including lipids, proteins, and DNA, dysfunction of cellular organs, and poor energy metabolism [21, 22].

Clogging theory illustrates that the accumulation of lactic acid and intracellular inorganic phosphate $(\mathrm{Pi})$ resulting from anaerobic respiration will affect cellular homeostasis and result in fatigue. When the maximal aerobic capacity is reached, the oxygen supply for oxidative phosphorylation of ATP production is insufficient. As a result, anaerobic respiration with nonoxidative phosphorylation increases to meet the body need, leading to the accumulation of lactic acid intracellularly. The $\mathrm{H}^{+}$ions from lactic acid inhibit energy metabolism as the key enzymes involved in glycolysis and gluconeogenesis are inhibited under low pH [23]. Apart from this, the acidosis will inhibit calcium ion pumping in sarcoplasmic reticulum and consequently reduce the degree of muscle contractile activation. Also, when burst of energy is needed for muscle, the hydrolysis of creatine phosphate which gives creatine and $\mathrm{Pi}$ will be involved in the anaerobic respiration. The muscle contraction force will decrease as $\mathrm{Pi}$ level increases, leading to the feeling of fatigue [24].

Hemoglobin theory suggests that cells and tissues may be damaged during strenuous exercise due to destruction of red blood cells caused by leakage of energy metabolic system coenzyme and myoglobin [25]. The destructed red blood cells cannot transport oxygen to the muscular tissues successfully, disturbing the production of ATP by aerobic respiration and causing fatigue.

\section{Mechanisms for Antifatigue Effects of Edible and Medicinal Mushrooms}

3.1. Muscular Function. The level of fatigue could be evaluated based on the energy metabolism of muscles [26]. Exercise endurance time is an important and straightforward variable in evaluating the antifatigue effect of edible and medicinal mushrooms. Swimming is the most commonly accepted experimental exercise model to evaluate the extent of muscular fatigue [27]. The swimming endurance time is normally defined as the time when mice keep the swimming activity until they sink into the bottom of swimming pool and stop moving for a certain time period (e.g., $10 \mathrm{~s}$ ) [28]. Other exercise models including rotating rod test and forced running test have also been adopted to evaluate the level of fatigue [29]. Edible and medicinal mushrooms function to mitigate muscular fatigue by affecting blood lactic acid and glycogen storage, blood urea nitrogen level, relevant enzyme activities, metabolic regulators, and expression of relevant transporters.

3.1.1. Lactic Acid and Glycogen Storage. Lactic acid is the product of glycolysis under anaerobic condition. The accumulation of lactic acid during exercise will inhibit energy metabolism and reduce muscular endurance, resulting in fatigue. Glycogen storage in liver and muscle is an important energy source to supply sufficient fuel for exercise. The hepatic glycogen can be converted into glucose and released into blood for energy supply when blood glucose level is low [30]. Therefore, blood lactic acid, muscle, and liver 
TABLE 1: Antifatigue effects of some common edible and medicinal mushrooms on mice [35].

\begin{tabular}{lccccc}
\hline Group & $\begin{array}{c}\text { Dosage } \\
(\mathrm{g} / \mathrm{kg} \text { feed })\end{array}$ & $\begin{array}{c}\text { BUN } \\
(\mathrm{mg} / \mathrm{dl})\end{array}$ & $\begin{array}{c}\text { Lactic acid } \\
(\mathrm{mg} / \mathrm{dl})\end{array}$ & $\begin{array}{c}\text { LDH } \\
(\mathrm{U} / \mathrm{dl})\end{array}$ & $\begin{array}{c}\text { Swimming } \\
\text { time }(\mathrm{min})\end{array}$ \\
\hline Control & 0.0 & $42.0 \pm 8.72$ & $65.2 \pm 19.41$ & $442 \pm 55.0$ & $221.0 \pm 68.4$ \\
L. edodes & 60.0 & $35.1 \pm 6.04$ & $47.5 \pm 12.50$ & $465 \pm 45.3$ & $295.1 \pm 95.8$ \\
H. erinaceus & 60.0 & $36.2 \pm 4.69$ & $46.0 \pm 13.62$ & $440 \pm 53.1$ & $290.5 \pm 89.2$ \\
T. fuciformis & 60.0 & $37.4 \pm 4.35$ & $48.5 \pm 12.45$ & $445 \pm 68.0$ & $294.2 \pm 84.3$ \\
G. lucidum & 30.0 & $31.5 \pm 5.15$ & $46.8 \pm 11.20$ & $518 \pm 50.2$ & $319.2 \pm 61.6$ \\
C. sinensis & 8.0 & $32.7 \pm 4.82$ & $43.7 \pm 13.00$ & $504 \pm 51.6$ & $308.5 \pm 69.3$ \\
\hline
\end{tabular}

glycogens are all important indicators judging the degree of fatigue [28, 31]. Edible and medicinal mushrooms have been demonstrated to mitigate fatigue through inhibiting blood lactic acid generation and increasing glycogen storage in liver and muscle. For instance, T. Li and W. Li found that the water extracts of Cordyceps sinensis can inhibit the production of lactic acid during exercise and increase liver and muscle glycogen storage with the dosage of $200 \mathrm{mg} / \mathrm{kg}$ polysaccharides from $C$. sinensis most effective in mice [32]. The extracts of submerged fermentation of Ganoderma lucidum were also found to inhibit the accumulation of blood lactic acid, accelerate lactic acid clearance, improve glycogen reserve, and reduce glycogen consumption during exercise, resulting in less fatigue [33].

3.1.2. Blood Urea Nitrogen. The blood urea nitrogen (BUN) is the nitrogen content in urine from the breakdown of proteins, which occurs when energy production from sugar and fat metabolism is insufficient to support the body. The body will remove such waste product from protein breakdown in order to maintain normal functioning of the body system. Therefore, the BUN level is also an important indicator showing the capability of body to suffer from physical load and fight against fatigue [34]. Many scholars use the BUN level to exhibit the antifatigue effect of edible and medicinal mushrooms. For instance, G. lucidum (directly used as powder with $60 \mathrm{~g} / \mathrm{kg}$ feed) can reduce the decomposition of protein for energy with BUN level decreased from $42.0 \mathrm{mg} / \mathrm{dl}$ of control to around $31.5 \mathrm{mg} / \mathrm{dl}$ after two-week treatment, indicating that G. lucidum can enhance energy metabolism from carbohydrate and fat to supply enough energy in order to limit protein breakdown [35]. Wu et al. found that the Hirsutella sinensis can also extend swimming time to exhaustion in rats and reduce blood lactate and BUN levels but did not have an effect on tissue glycogen [36]. Wu and coworkers found that the mycelium hot water extracts of Ophiocordyceps sinensis could increase the swimming endurance of mice up to $100 \%$ and also increase glycogen level and reduce lactic acid and BUN levels significantly [37]. The water extracts of Agaricus bisporus with the dosage of $120 \mathrm{mg} / \mathrm{kd} \cdot \mathrm{d}$ in mice also showed effect on BUN reduction of about $46 \%$ compared with the control group, indicating better nutrient circulation to avoid fatigue [38].

3.1.3. Lactate Dehydrogenase Activity. Lactate dehydrogenase (LDH) is an enzyme found in almost all body tissues involved in cellular respiration. It is involved in the process known as the Cori cycle. The increase in LDH activity can help to produce enough ATP for exercise under anaerobic condition and speed up the removal of lactic acid [35]. Liang and coworkers found that the LDH activity can be significantly stimulated by G. lucidum. Compared with the control group with LDH activity of around $442 \mathrm{U} / \mathrm{dl}$, the G. lucidum treated mice group had LDH of around $518 \mathrm{U} / \mathrm{dl}$. The LDH activities of other edible and medicinal mushrooms were also compared by Liang et al. together with the BUN level, lactic acid level, and swimming time (Table 1). Results show that $G$. lucidum, C. sinensis, Lentinus edodes, Tremella fuciformis, and Hericium erinaceus could all effectively increase swimming endurance and reduce BUN and lactic acid level, with G. lucidum and C. sinensis showing most significant stimulating effect on LDH activity [35].

3.1.4. Skeletal Muscle Metabolic Regulators and Transporters. Kumar and coworkers studied the antifatigue activity of $C$. sinensis in the molecular level and found that $C$. sinensis could enhance muscle endurance by promoting the expression of skeletal muscle key metabolic regulators AMPK, PGC$1 \alpha$, and PPAR- $\delta$ (Figure 1) [39]. These genes could induce marked changes in skeletal muscle metabolism, including increases in glycogen breakdown, glycolysis, glucose uptake, and oxidation of fatty acid, together with many changes in gene expression promoting endurance [40]. AMPK is an AMP-activated protein kinase, which was activated in muscle during exercise and electrically stimulated contraction. High AMPK activity can lead to higher basal glucose uptake [40]. PGC- $1 \alpha$ is a transcriptional coactivator that can activate the oxidative metabolism and biogenesis in mitochondria. The activation of PGC- $1 \alpha$ drives the conversion of muscle fiber type II to type I fibers which are slow twitch muscle fibers with higher oxidative capacity. They can use oxygen more efficiently to produce more ATP for continuous muscle contractions and are more resistant to fatigue [41]. PPAR$\delta$ is the transcriptional regulator for fatty acid oxidation in adipose tissue by activating the enzyme associated with long chain fatty acid $\beta$ oxidation. It is able to drive fatty acid transport and oxidation, increase the formation of type I muscle, and enhance heart contraction function and thus can improve physical endurance and performance [42].

Meanwhile, Kumar et al. [39] also found that C. sinensis was capable of stimulating the expression of lactate monocarboxylate transporter MCT1 and glucose transporter GLUT4 


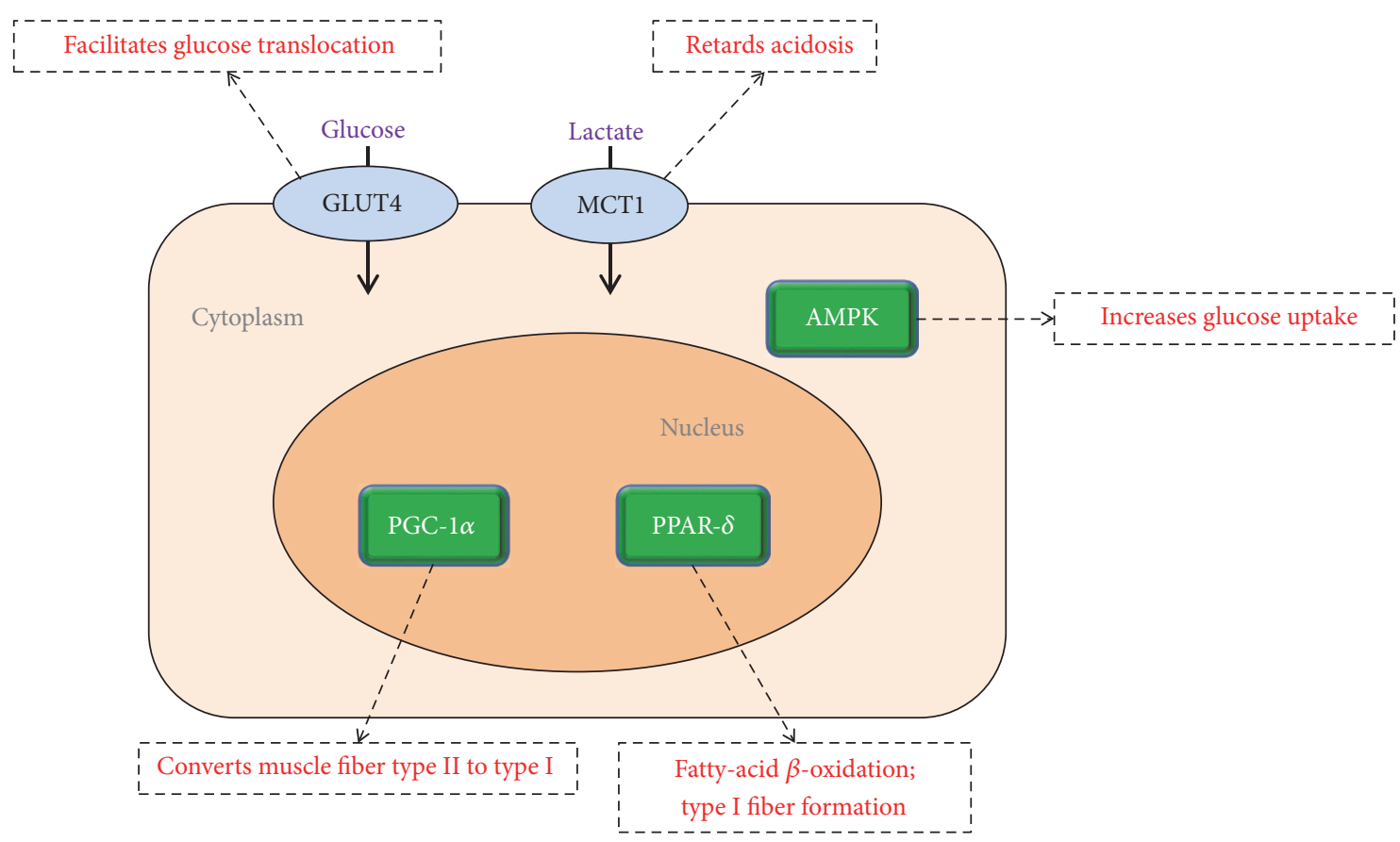

Skeletal metabolic regulators

Figure 1: A possible mechanism with skeletal muscle metabolic regulators and transporters for the muscle endurance enhancement with a medicinal mushroom C. sinensis (adapted from [39]).

(Figure 1). When lactic acid accumulation occurs during exercise, it dissociates to form lactate and hydrogen ions, leading to acidosis and fatigue. Lactate can help to retard acidosis and inhibit fatigue because it acts as a buffer to the protons accumulated during exercise. MCT1 can facilitate the lactate transport into skeletal muscle. GLUT4 is a glucose transporter found in adipose tissue and striated muscle. It is induced by insulin signal to facilitate the translocation of glucose into cell. Therefore, the effective expression of MCT1 and GLUT4 could retard acidosis and enhance glucose transport in skeletal muscle, so that muscle endurance could be improved [39]. The medicinal mushroom of Phellinus linteus has also been found to increase endurance exercise performance through increasing the expression of MCT1 and MCT4 in muscles [43].

\subsection{Antioxidant Effect}

3.2.1. Free Radical Scavenging Activity. Reactive oxygen species (ROS) is the byproduct from the oxidative reaction of ATP production in mitochondria. Although organisms can generate antioxidant and have repair systems that can protect them from oxidative damage, the condition of fatigue will weaken the antioxidant system, resulting in excess free radicals and increase of oxidative stress. The oxidative stress of cells reduced by the free radical scavenging ability of edible and medicinal mushrooms can help to enhance energy metabolism in mitochondria, which can accelerate energy production rate and help to mitigate fatigue. The antioxidant activity of edible and medicinal mushrooms could be evaluated in vitro through the scavenging of 2,2-diphenyl-1picrylhydrazyl (DPPH), hydroxyl radical, superoxide anion radical, nitric oxide, and the inhibition effect on lipid peroxidation. The hydroxyl and superoxide anion could be generated by the mitochondria during respiration, which may impair cellular structures and functions if they are produced in excess. Nitric oxide could react with the superoxide anion generated and form peroxynitrite. Peroxynitrite is a highly reactive oxidant and nitrating agent, which could damage a wide array of cellular molecules including proteins and DNA. Lipid peroxidation is the oxidative degradation of lipids in cell membranes, which also causes cell damage [45].

The antioxidant activities of edible and medicinal mushrooms are evaluated based on the above-mentioned aspects. For instance, researchers found that the hot water extracts of $C$. sinensis exhibited DPPH, hydroxyl, and superoxide anion radical scavenging activity with the inhibition effects increasing with doses [46]. Joseph and coworkers found that the chloroform extracts of G. lucidum were able to scavenge the reactive oxygen species and enhance body antioxidant defense. With $1000 \mu \mathrm{g} / \mathrm{ml}$ chloroform extract of G. lucidum, the DPPH scavenging activity could reach around $91.1 \%$. Meanwhile, the chloroform extract could also inhibit lipid peroxidation and scavenge superoxide anion and nitric oxide, preventing the cell membrane and cellular molecules from damage [47]. The studies of Chen suggested that polysaccharides from $T$. fuciformis also had scavenging activity on the superoxide anion and hydroxyl radical, which 
can effectively reduce the formation of highly reactive oxidant peroxynitrite and mitigate biomolecules damage. The superoxide scavenging activity increased from 17 to $90 \%$ with increasing polysaccharide concentration in T. fuciformis from 0.1 to $0.4 \mathrm{mg} / \mathrm{ml}[48]$.

\subsubsection{Enhancing Antioxidant Enzyme Activity. Researchers} found that edible and medicinal mushrooms can stimulate the activities of antioxidant enzymes, such as superoxide dismutase (SOD), glutathione peroxidase (GSH-Px), glutathione reductase, and catalase, to prevent oxidative stress and fatigue. SOD is a natural enzyme that can neutralize specifically superoxide radicals by utilizing different positively charged metal ions like copper or zinc. GSH-Px is also a natural antioxidant enzyme which can scavenge and inactivate hydroxyl radicals. Glutathione reductase and GSHPx make up the glutathione system of antioxidant enzymes to reduce lipid hydroperoxides and free hydrogen peroxides. Catalase is an antioxidant enzyme working with SOD to prevent free radical damage. SOD converts superoxide radicals to hydrogen peroxides and catalase converts them into harmless water and oxygen [49].

$\mathrm{Ma}$ et al. stated that polysaccharides from T. fuciformis can stimulate the formation and activity of the enzymes of SOD and GSH-Px, demonstrating potent antioxidant activity of $T$. fuciformis to prevent oxidative stress [50]. The polysaccharides from $L$. edodes were figured out to stimulate the activity of SOD and GSH-Px. Besides, the blood malondialdehyde (MDA) level of $L$. edodes treated mice was lower than that of the control group, indicating that the oxidative damage resulting from ROS attack was limited. Therefore, $L$. edodes can help to limit oxidative damage on cell effectively [49]. The water extracts of $A$. bisporus were also found to significantly stimulate the activities of catalase, glutathione reductase, and GSH-Px, which contributed to the antioxidant effect of $A$. bisporus [51].

Through effective scavenging of free radicals and enhancement of antioxidant enzyme activities, edible and medicinal mushrooms could protect tissues from exercise-induced oxidative damage, thus reducing physical fatigue.

3.3. Cardiovascular Function. The cardiovascular system includes the heart and two networks of blood vessels. The contraction of heart provides an arterial blood pressure to push blood throughout the body. The circulation of blood through blood vessels network transports nutrients and oxygen to individual cells and removes waste products for disposal [52]. The proper functioning of cardiovascular system is one of the essential factors to prevent fatigue.

Edible and medicinal mushrooms can promote and enhance blood circulation by vasodilation, that is, the expansion of blood vessels when the smooth muscles of vessel wall relax. The dilation of blood vessel can be induced by vasodilators in single organ or throughout the entire body. Therefore, vasodilation can be controlled to occur in areas that need blood supply increase, helping the body to keep tissues alive and function properly [52].
C. sinensis is a typical medicinal mushroom which has been found to have vasodilation effect on blood vessels. It helps to avoid fatigue by redistribution and increase blood flow to supply enough oxygen and nutrients to essential organs and muscles. Feng and coworkers found that the aqueous phosphate buffer saline extracts of $C$. sinensis can stimulate nitric oxide production and endothelium-derived hyperpolarizing factor (EDHF) to reduce arterial pressure and induce the endothelium-dependent vasodilation effect [53]. The active component of adenosine in G. lucidum has also been found as an important contributor to vasodilation, which can reduce blood viscosity, inhibit platelet aggregation, and improve blood oxygen supply capacity [54]. When body is supplied with sufficient energy from the cardiovascular system, the condition of fatigue could usually be effectively alleviated.

3.4. Immunomodulation. The immune system is a complex system that can remember and recognize pathogens and produce cells and secretions to remove them with high specificity. The active substances in edible and medicinal mushrooms can improve the immune system by activating immune effector cells including macrophages, natural killer cells, and T cells. A well-performed immune system can ensure proper functioning of other body systems and adequate amount of energy supply to each part of body so as to prevent fatigue. The immunomodulation effect of edible and medicinal mushrooms is achieved mainly through the following mechanisms.

3.4.1. Activation of Macrophages. Macrophages are white blood cells constituting the first-line defense of body to engulf foreign invaders. In the studies of Wang et al., G. lucidum can activate macrophages, lymphocytes, and other immune cells to respond to pathogens [55]. Jia and Lau also found that $C$. sinensis could enhance phagocytosis of macrophages, which removed foreign pathogens and triggered specific activities of other immune cells more effectively [56].

3.4.2. Increase of $T$ Helper Cells and Ratio of $T$ Helper: $T$ Suppressor Cells. T helper cells are one kind of lymphocytes that have no cytotoxic or phagocytic activity to kill pathogens or infected cells. They play an important role in the immune system which controls and regulates the other immune cells to respond to foreign invaders. The $\mathrm{T}$ suppressor cells are a subpopulation of T cells that can maintain homeostasis of the immune system and avoid immune response towards selfantigen. The increase in $\mathrm{T}$ helper: $\mathrm{T}$ suppressor cells means enhancement in immune system activity. It has been found by Chen and coworkers that the number of T helper cells and ratio of $\mathrm{T}$ helper: $\mathrm{T}$ suppressor cells in mice can be increased by treatment with the ethanol extracts of $C$. sinensis [57].

3.4.3. Increase of Natural Killer Cells Activity and Cytokines Expression. Natural killer cells belong to cytotoxic lymphocytes which have their own specific mechanism to identify foreign invaders and remove them. They can kill infected cells or even cancer cells by triggering various cell destroying mechanisms. Cytokines are a category of signaling molecules 
used for cellular communication. They are released by different immune cells to regulate immune response in infective sites. C. sinensis has been proved to enhance the activity of natural killer cells and increase the production of cytokines [57]. Mao and coworkers figured out that G. lucidum can stimulate the expression of cytokines and the proliferation of T lymphocytes [58]. Wu et al. found that dietary supplementation with $A$. bisporus can enhance the activity of natural killer cells and the production of cytokines as well [59].

The immunomodulation effect of edible and medicinal mushrooms helps to ensure a well-performed immune system for the whole body to function properly so as to lower the occurrence of fatigue.

3.5. Hormone Regulation. Hormone is a chemical released by cells or glands, which is responsible for message transfer to affect cells in other parts of the body. Testosterone is a steroid hormone primarily secreted by the Leydig cells of men testes and women ovaries. High testosterone level leads to improvement in muscle development and high energy level. However, significantly high testosterone level also causes side effects including dysfunction of liver and cardiovascular system [60]. The active compounds in edible and medicinal mushrooms can either simulate or inhibit testosterone production depending on the mushroom species, which helps to balance the testosterone level and maintain body energy level to prevent fatigue.

Different medicinal mushrooms have different effect on the production of testosterone. Huang and coworkers suggested that $C$. sinensis can stimulate the production of testosterone in mice Leydig cells through the stimulation of steroidogenesis with $3 \mathrm{mg} / \mathrm{ml}$ inducing the maximal production rate [61]. G. lucidum was found to exhibit hormone regulation activity, which reduces testosterone activity when it is abnormally high and affects normal energy metabolism [62].

3.6. Hepatic Function. Liver is a very important organ responsible for many critical functions. Glucose is stored in liver in the form of glycogen. The liver will release glucose when body needs extra amount of energy. The liver also acts as blood filter to remove toxins in blood and produce cleaner blood which can carry more oxygen and nutrients. The fat metabolism of liver is also important to maintain healthy cardiovascular system and body weight. All these functions of liver are closely related to the proper functioning of body. The dysfunction of liver will have a negative impact on energy metabolism and can therefore lead to fatigue. Edible and medicinal mushrooms have been reported to improve hepatic function from the following aspects.

3.6.1. Increase of Liver Energy State. The study of Manabe et al. found that the hot water extracts of $C$. sinensis can increase liver ATP to Pi ratio which represents high energy state of liver, and increase liver blood flow. The C. sinensis extracts can increase the energy content in liver cell because they induce the relaxation of liver blood vessels, leading to increase in liver blood flow. In this case, the liver can work effectively to promote blood circulation and clean blood to carry more oxygen and nutrient for energy metabolism in mitochondria [63].

3.6.2. Promotion of Liver Protein and RNA Synthesis. Edible and medicinal mushrooms have also been found to promote protein and RNA synthesis, which helps to maintain the normal function of liver and avoid fatigue. For instance, Y. Wei and C. Zheng reported that T. fuciformis can promote the leucine incorporation into liver protein and orotic acid incorporation into RNA in liver cells of mice [64].

3.7. Blood Glucose Regulation. The blood glucose level is maintained through the actions of two pancreatic hormones, insulin and glucagon. Insulin functions to reduce blood glucose back to normal by stimulating body cells to increase glucose uptake rate, increase cell glucose metabolism, increase glycogen formation from glucose in liver, and increase fat synthesis from glucose in liver and adipose cells. Glucagon works in the opposite way to increase blood glucose to the normal level. Abnormally high blood glucose level may lead to hyperglycemia and diabetes which can result in heart disease or kidney failure, while abnormally low blood glucose level may lead to hypoglycemia which is usually associated with chronic fatigue.

Edible and medicinal mushrooms are capable of stabilizing blood glucose level so as to avoid fatigue. Their hypoglycemic effect is achieved mainly through the increase of circulating insulin or relevant enzyme activities. For instance, $\mathrm{Li}$ and coworkers found that, with the administration of CSP1 , a kind of polysaccharides in C. sinensis, significant effect on blood insulin increase was observed. With the dose of $400 \mathrm{mg} / \mathrm{kg}$ body weight of CSP-1, the blood glucose level was reduced from 6.09 to $4.72 \mathrm{mmol} / \mathrm{l}$ and the insulin level was increased from 10 to $15.3 \mathrm{mlU} / 1$ after 7-day treatment [65]. Kiho et al. found that the alkaline extracts of $C$. sinensis had hypoglycemic effect through increasing the enzyme activities of glucokinase, hexokinase, and glucose-6-phosphate dehydrogenase [66]. Kiho and coworkers found similar effect from Tremella aurantia which could also improve relevant enzyme activities to regulate blood glucose level [67]. Increasing blood insulin and enhancing the activities of these enzymes can effectively increase cell glucose metabolic rate and promote blood oxygen and nutrient transport so as to mitigate fatigue. Figure 2 summarizes the physiological basis of fatigue and the antifatigue mechanisms of edible and medicinal mushrooms in a more explicit way, with the detailed antifatigue mechanisms summarized in Table 2.

Previous studies have demonstrated that $C$. sinensis and G. lucidum are two representative antifatigue mushrooms because they can work in various biological systems. Based on the above review, their antifatigue mechanisms are summarized as follows. C. sinensis can increase glycogen storage and limit the accumulation of lactic acid in blood. It also enhances the expression of muscle metabolic regulators as well as lactate and glucose transporters to promote energy utilization and retard acidosis in muscle. C. sinensis can also scavenge free radicals generated during oxidative metabolism and stimulate vasodilation. Besides, it is also capable of improving energy state of liver, stimulating body testosterone level, and 


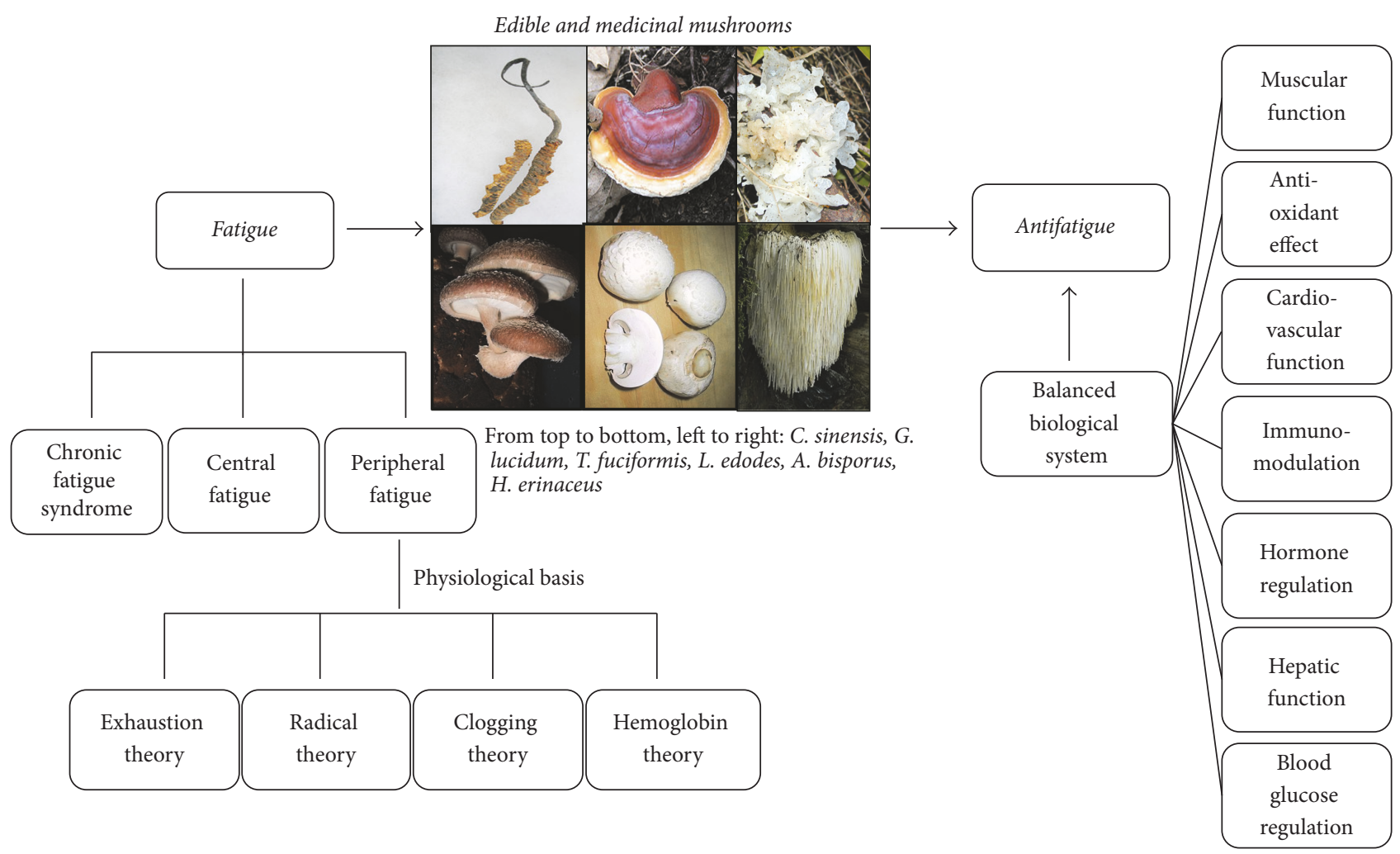

FIGURE 2: Illustration of physiological basis of fatigue and antifatigue mechanisms of edible and medicinal mushrooms (photos obtained from Wikipedia).

TABLE 2: Summary of the antifatigue functions and possible mechanisms of mushrooms.

\begin{tabular}{|c|c|}
\hline $\begin{array}{l}\text { Antifatigue functions of } \\
\text { mushrooms }\end{array}$ & Detailed mechanisms \\
\hline Muscular function improvement & $\begin{array}{l}\text { (i) Inhibits production and accelerate clearance of lactic acid; } \\
\text { (ii) Increases glycogen storage in liver and muscle; } \\
\text { (iii) Reduces blood urea nitrogen from protein breakdown; } \\
\text { (iv) Increases lactate dehydrogenase activity; } \\
\text { (v) Promotes the expression of skeletal muscle key metabolic regulators of AMPK, PGC- } 1 \alpha \text {, and } \\
\text { PPAR- } \delta \text {; } \\
\text { (vi) Stimulates the expression of lactate monocarboxylate transporter and glucose transporter. }\end{array}$ \\
\hline Antioxidant function & $\begin{array}{l}\text { (i) Scavenges DPPH, hydroxyl radical, superoxide anion radical, and nitric oxide; } \\
\text { (ii) Inhibits lipid peroxidation; } \\
\text { (iii) Stimulates antioxidant enzymes of SOD, GSH-Px, catalase, and glutathione reductase. }\end{array}$ \\
\hline $\begin{array}{l}\text { Cardiovascular function } \\
\text { improvement }\end{array}$ & (i) Vasodilation in areas that need blood supply increase. \\
\hline $\begin{array}{l}\text { Immunomodulation } \\
\text { enhancement }\end{array}$ & $\begin{array}{l}\text { (i) Activates macrophages to engulf foreign invaders; } \\
\text { (ii) Increases T helper cells to control and regulate other immune cells; } \\
\text { (iii) Increases T helper: T suppressor cells to enhance immune system activity; } \\
\text { (iv) Increases natural kill cells activity to identify and remove foreign invaders; } \\
\text { (v) Improves cytokines expression to regulate cellular communication and immune response in } \\
\text { infective sites. }\end{array}$ \\
\hline $\begin{array}{l}\text { Hormone regulation } \\
\text { improvement }\end{array}$ & (i) Balances testosterone level to improve muscle development. \\
\hline Hepatic function improvement & $\begin{array}{l}\text { (i) Increases energy state by increasing ATP to Pi ratio; } \\
\text { (ii) Increases liver blood flow; } \\
\text { (iii) Promotes liver protein and RNA synthesis. }\end{array}$ \\
\hline $\begin{array}{l}\text { Blood glucose regulation } \\
\text { improvement }\end{array}$ & $\begin{array}{l}\text { (i) Increases circulating insulin to reduce glucose back to normal; } \\
\text { (ii) Increases relevant enzyme activities including glucokinase, hexokinase, and glucose-6-phosphate } \\
\text { dehydrogenase to increase glucose metabolic rate. }\end{array}$ \\
\hline
\end{tabular}


regulating blood glucose level. The cytokines expression and activities of immune cells including macrophages, natural killer cells, and T helper cells are enhanced by C. sinensis as well. All these effects support that $C$. sinensis can strongly enhance body fatigue resistance.

G. lucidum can increase glycogen storage, improve BUN clearance rate, limit lactic acid accumulation, and significantly improve LDH activity. It can also inhibit lipid peroxidation and scavenge nitric oxide and superoxide anion. Besides, G. lucidum is capable of stimulating macrophage activities and the expression of cytokines, as well as balancing body testosterone level. Vasodilation could also be induced by G. lucidum, which reduces blood viscosity, inhibits platelet aggregation, and improves blood transport efficiency. These pharmacological effects of G. lucidum make it an effective antifatigue mushroom as well.

\section{Polysaccharides as Active Components of Edible and Medicinal Mushrooms for Antifatigue Effect}

Polysaccharides are very important components in edible and medicinal mushrooms. The bioactive polysaccharides isolated from mushrooms include homopolysaccharides commonly extracted as glucans and heteropolysaccharides with different compositions and types of glycosidic linkages. Some are bound with protein or peptide residues forming polysaccharide-protein or polysaccharide-peptide complexes [68]. Polysaccharides in edible and medicinal mushrooms could mitigate fatigue through the improvement on muscular function, antioxidant effect, blood glucose regulation, immunomodulation, and hormone regulation.

4.1. Homopolysaccharides. Homopolysaccharides have been isolated from edible and medicinal mushrooms by many researchers. The polysaccharide of G. lucidum was found to be $\beta$-D-glucan, which was a potent stimulator for macrophages, helping them with nitric oxide release to kill pathogens more effectively [55]. Zhonghui et al. found strong evidence that the polysaccharide from G. lucidum possessed protective effects against exhaustive exercise-induced oxidative stress through increasing antioxidant enzymes activities and decreasing malondialdehyde (MDA) levels in the skeletal muscles of mice [69]. The polysaccharides from A. bisporus, especially $\beta$-1,3-glucans (Figure 3(a)), were discovered as the bioactive molecules for immunomodulation enhancement, which functioned by improving the natural killer cell activities [59]. Bobovčák et al. found that the $\beta$-glucan from Pleurotus ostreatus could modulate exercise-induced changes in natural killer cell activities (NKCA) in intensively training athletes. They found that, after intense exercise, the placebo group showed a $28 \%$ reduction in NKCA below the baseline value, whereas the group treated with $\beta$-glucan from $P$. ostreatus had no significant reduction in NKCA [70]. A new water soluble glucan with a molecular weight of around $1.48 \times 10^{5} \mathrm{Da}$ was obtained by Maity and coworkers from the hot water extracts of Meripilus giganteus, showing hydroxyl and superoxide radicals scavenging activity [71]. Maity et al. isolated a water soluble $\beta$-glucan from the hot water extracts of Entoloma lividoalbum fruit bodies, which exhibited strong immunomodulation effect by stimulating macrophage, splenocyte, and thymocyte. Meanwhile, promising antioxidant activities of the isolated $\beta$-glucan were observed as evidenced from its hydroxyl and superoxide radicals scavenging activities [72].

4.2. Heteropolysaccharides. The polysaccharides isolated from edible and medicinal mushrooms could also be heteropolysaccharides. Polysaccharides from C. sinensis CSP1 composed of glucose, mannose, and galactose in the ratio of $1: 0.6: 0.75$ with molecular weight of $210 \mathrm{kDa}$ demonstrated hypoglycemic effect by increasing glucose metabolic rate [65]. Other research showed that the polysaccharides from C. sinensis were effective in improving swimming endurance time of mice through inhibiting lactic acid production during exercise and increasing liver and muscle glycogen storage [32]. The body testosterone level could also be stimulated by polysaccharides of $C$. sinensis to boost body energy level [61]. A heteropolysaccharide of T. fuciformis with the backbone chain of $\alpha$ - $(1 \rightarrow 3)$-linked D-mannan and small xylose- and glucuronic acid-containing side chains was found to stimulate the formation and activity of SOD and GSH-Px enzymes and effectively scavenge free radicals $[48,50]$. The studies of Xin et al. found that T. fuciformis polysaccharides can help to prolong the time for skeletal muscles to become fatigued with the concentration of $0.10 \%$ treated muscle showing the longest time to be fatigue [73]. Meanwhile, the polysaccharides from T. fuciformis were also found to enhance transcription in liver cells, which promoted liver protein synthesis and helped to maintain the normal function of liver [64]. L. edodes polysaccharides mainly consisting of mannose, glucose, and galactose were found to scavenge excess superoxide anion and hydroxyl radicals produced during aerobic respiration [74] and promote the production of antioxidant enzymes, especially GSH-Px [49]. Siu et al. purified two polysaccharides from wild Armillaria ostoyae. One was composed solely of glucose; the other was a branched galactoglucan with glucose and galactose at the molar ratio of $6: 1$, exhibiting a more significant antioxidant capacity [75]. Three types of polysaccharides were purified from Flammulina velutipes with molecular weights of 9,930,62,290, and $36,310 \mathrm{Da}$, respectively, with the latter two showing higher antioxidant activities. All of these polysaccharides were heteropolysaccharides comprising glucose, galactose, mannose, and xylose with different molar ratios [76]. Manna and coworkers isolated a water soluble heteroglycan ( $\mathrm{Mw}$ around $60 \mathrm{kDa}$ ) from the hot aqueous extract of Lentinus fusipes. The heteroglycan was found to be composed of D-galactose and D-glucose in the molar ratio of approximately $1: 1$, showing both in vitro splenocyte and macrophage activation and DPPH radical scavenging activity [77].

4.3. Polysaccharide-Protein or Polysaccharide-Peptide Complexes. Polysaccharide-protein or polysaccharide-peptide complexes isolated from edible and medicinal mushrooms also exhibit antifatigue functions. Zhang and coworkers investigated the polysaccharide extracts from Ganoderma 


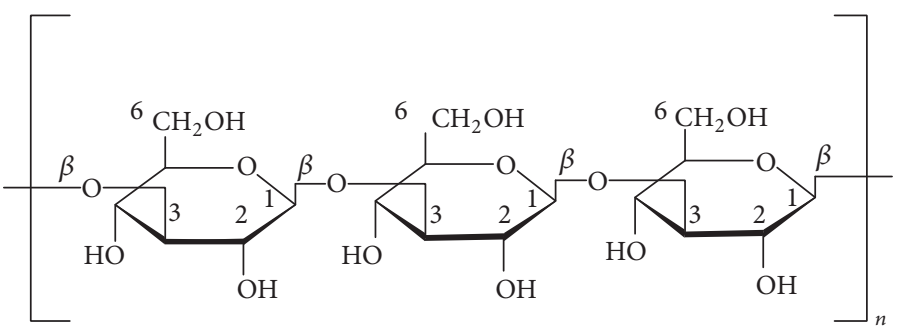

$\beta$-1,3-Glucan

(a)

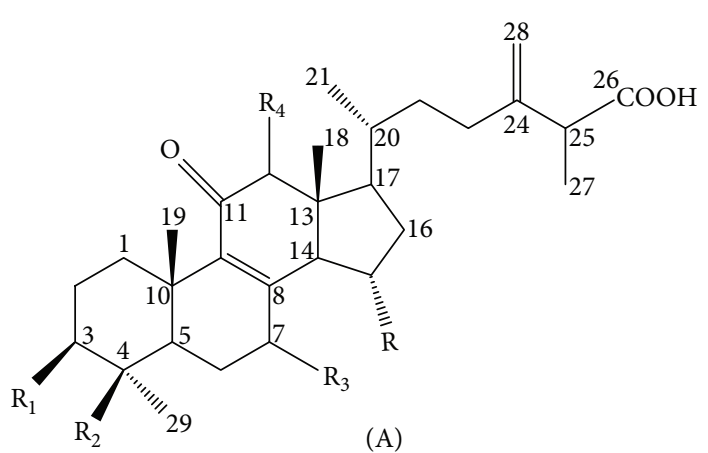

(A)

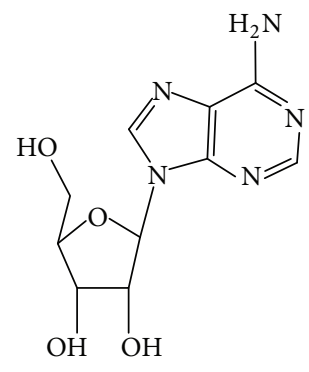

Adenosine

(b)

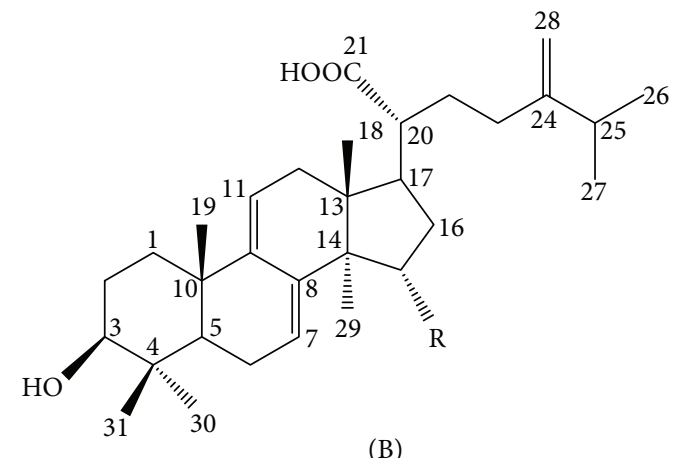

Triterpenoid

(c)<smiles>O=c1oc(/C=C/c2ccc(O)c(O)c2)cc(O)c1-c1cc(O)c(O)cc1/C=C/c1cc2oc(=O)c3cc(O)c(O)cc3c2c(=O)o1</smiles><smiles>O=c1cc([Tl])oc(-c2cc(O)c(O)cc2-c2c(O)cc(/C=C/c3ccc(O)c(O)c3)oc2=O)c1</smiles><smiles>CC1=CC(=O)C2(O1)C(c1cc3oc(=O)c4cc(O)c(O)cc4c3c(=O)o1)=Cc1cc(O)c(O)cc12</smiles>

3

5<smiles>CC(=O)C1(O)C(c2cc3oc(=O)c4cc(O)c(O)cc4c3c(=O)o2)=Cc2cc(O)c(O)cc21</smiles>

2<smiles>O=c1oc(=O)c2cc(/C=C/c3ccc(O)c(O)c3)oc(=O)c2c2cc(O)c(O)cc12</smiles>

4<smiles>O=C1C=C(C=Cc2ccc(O)c(O)c2)OC12C(c1cc3oc(=O)c4cc(O)c(O)cc4c3c(=O)o1)=Cc1cc(O)c(O)cc12</smiles>

6

Polyphenol

(d)

Figure 3: Typical structures of bioactive molecules in edible and medicinal mushrooms. (a) $\beta$-1,3-Glucan, (b) adenosine, (c) triterpenoids from Antrodia camphorate with (A) ergostane type and (B) lanostane type [12], and (d) polyphenol from Inonotus obliquus with 1, 2, 3 as inonoblins and 4, 5, 6 as phelligridins [44]. 
atrum and figured out that its antioxidant activities were ascribed to the phenolic and protein components of the polysaccharide conjugates, while the immune-modulatory activity should be more attributed to the $(1 \rightarrow 3,1 \rightarrow 6)$ linked-heteroglucan structure [78]. It was mainly composed of mannose, galactose, and glucose in the molar ratio of $1: 1.28: 4.91$, with an average molecular weight of about $1,013 \mathrm{kDa}$ [79]. Li and coworkers purified a novel $16 \mathrm{kDa}$ polysaccharide-peptide complex from Pleurotus abalones with the monosaccharide composition characterized as glucose, rhamnose, glucuronic acid, and galactose in the molar ratio of $22.4: 1: 1.7: 1.6$. The peptide component with $\mathrm{N}$-terminal amino acid sequence showed similarity to antioxidant enzymes, indicating that the antioxidant function of $P$. abalones may come from the peptide component of the polysaccharide-peptide complex [80]. Wu and coworkers studied C. sinensis Cs-HK1 and found that the carbohydrate moiety of the exopolysaccharide (EPS) was mainly composed of glucose and mannose at the mole ratio of 3.2:1.0. The glycopeptides component of the EPS with an average molecular weight of $6.0 \mathrm{kDa}$ showed remarkable antioxidant capacity [81]. A summary of representative research on polysaccharides in edible and medicinal mushrooms for fatigue mitigation is shown in Table 3.

From the major functions of polysaccharides in edible and medicinal mushrooms such as inhibiting lactic acid formation, increasing glycogen storage, hormone regulation, blood glucose regulation, antioxidant, and immunomodulation, the body will function in a balanced way with efficient energy to fight against fatigue.

\section{Other Bioactive Constituents of Mushrooms for Antifatigue Effect}

5.1. Peptide and Proteins. The major roles of peptide and proteins of edible and medicinal mushrooms include the improvement on cardiovascular function, immunomodulation, and antioxidant effect. The polypeptide macromolecule in the aqueous phosphate buffer saline extracts of $C$. sinensis was found to stimulate nitric oxide production and EDHF to induce vasodilation effect and improve cardiovascular function. It redistributed blood to supply adequate amount of oxygen and nutrients to muscles and promoted blood circulation to remove waste products in muscles. The polypeptides also improved the energy state of liver, helping it with blood circulation and blood cleaning to carry more oxygen and nutrients throughout the body [53]. The protein, Ling Zhi8 (LZ-8), found in G. lucidum extracts was found to help $\mathrm{T}$ lymphocytes to respond to cytokines more effectively so as to enhance the immunomodulation effect [84]. The peptides and crude proteins isolated from G. lucidum were also demonstrated to have antioxidant effect [11, 91]. Girjal and coworkers found that the amino acid composition of the peptide in G. lucidum was rich in phenylalanine, aspartic acid, proline, histidine, and isoleucine [11]. Geng and coworkers isolated an angiotensin converting enzyme inhibitory peptide from the crude water extracts of the fruiting bodies of Tricholoma matsutake, having antihypertensive effect to improve the cardiovascular function. This peptide was also demonstrated to have antioxidant effect as well through exhibiting DPPH radical scavenging activity [89].

5.2. Adenosine. Adenosine is a purine nucleoside consisting of ribose and adenine (Figure 3(b)). It is one of nucleotides of DNA and the molecular component of ATP, ADP, and AMP which have important roles in the biochemical processes like energy transfer and signal transduction. The studies on adenosine reported that it can reduce blood viscosity and improve blood oxygen supply capacity [54]. Adenosine has been found in many medicinal mushrooms such as C. sinensis and G. lucidum. Because adenosine hinders calcium ions uptake by muscle cells and causes intracellular interference, the contraction of smooth vessel muscles is inhibited, which triggers vasodilation and increment of oxygenated blood to the muscle cells [90]. Yoshioka and coworkers found that the adenosine isolated from Grifola gargal could promote glucose uptake in skeletal muscle cells [13]. The studies of Kawagishi et al. on G. lucidum adenosine suggested that adenosine can also have an inhibitory activity to platelet aggregation, which is the clumping of platelet in blood leading to the formation of clot [86]. The aggregation inhibition property of adenosine may help to enhance blood circulation and mitigate fatigue.

5.3. Triterpenoids. The studies of Zhu et al. suggested that the triterpenoids extracted from G. lucidum were the active components contributing to the antioxidant effect. The triterpenoids can significantly inhibit lipid peroxidation and prevent the formation of peroxynitrite through scavenging nitric oxide and superoxide anion [85]. They could also help to regulate the body testosterone level especially when the level was abnormally high by inhibiting the production of $5 \alpha$-reductase which was an important enzyme to activate testosterone [62]. Huang and coworkers found that Antrodia camphorate also had a great proportion of triterpenoid compound, namely, ergostane and lanostane skeleton triterpenoids (Figure 3(c)), in the bioactive extracts. They had obvious antifatigue activity with dose-dependently increased swimming time, blood glucose, and muscular and hepatic glycogen levels as well as dose-dependently decreased plasma lactate, ammonia levels, and creatine kinase activity [12].

5.4. Phenolic/Flavonoid Compounds. Islam and coworkers studied 43 commonly consumed mushrooms in China and figured out a high correlation between the antioxidant capacity and phenolic/flavonoid content. Among these edible mushrooms, Boletus aereus, Phellinus igniarius, Umbilicaria esculenta, Grifola frondosa, and Chroogomphus rutilus have relatively higher total phenolic and flavonoid contents and show comparatively higher antioxidant capacities [14]. Researchers found that the methanolic extracts of $A$. bisporus, which contained gallic acid, flavonoid, ascorbic acid, and phenolic compounds, can act as free radical scavengers and contribute to its potent antioxidant activity $[87,88]$. The polyphenol components isolated from the fruiting body of Inonotus obliquus, namely, inonoblins and phelligridins (Figure 3(d)), were also demonstrated to exhibit significant DPPH radical scavenging and moderate superoxide radical anion scavenging activities [44]. 
TABLE 3: Polysaccharides from edible and medicinal mushrooms for fatigue mitigation.

\begin{tabular}{|c|c|c|c|c|}
\hline Family & Species & Polysaccharide composition & Mechanism for anti-fatigue & Ref. \\
\hline Ganodermataceae & Ganoderma lucidum & $\beta$-D-Glucan & $\begin{array}{c}\text { Stimulates macrophages activity; } \\
\text { Promotes antioxidant enzyme activity. }\end{array}$ & {$[55,69]$} \\
\hline Agaricaceae & Agaricus bisporus & $\beta$-1,3-Glucan & Improves natural killer cell activities. & {$[59]$} \\
\hline Pleurotaceae & Pleurotus ostreatus & $\beta$-Glucan & $\begin{array}{c}\text { Modulates changes in natural killer cell } \\
\text { activities. }\end{array}$ & [70] \\
\hline Meripilaceae & Meripilus giganteus & Glucan, $\mathrm{Mw}$ of $1.48 \times 10^{5} \mathrm{Da}$ & Strong free radical scavenging activity. & [71] \\
\hline Entolomataceae & Entoloma lividoalbum & $\beta$-Glucan & $\begin{array}{l}\text { Stimulates macrophage, splenocyte, and } \\
\text { thymocyte; } \\
\text { Strong free radical scavenging activity. }\end{array}$ & {$[72]$} \\
\hline Cordycipitaceae & Cordyceps sinensis & $\begin{array}{c}\text { CSP- } 1 \text { with glucose, } \\
\text { mannose, and galactose in } \\
\text { the ratio of } 1: 0.6: 0.75 ; \\
\text { EPS-glycopeptide complex } \\
\text { with EPS comprising glucose } \\
\text { and mannose in the ratio of } \\
3.2: 1.0 \text { and glycopeptide } \\
\text { having Mw of } 6.0 \mathrm{kDa}\end{array}$ & $\begin{array}{l}\text { Hypoglycemic effect; } \\
\text { Inhibits lactic acid production and } \\
\text { increase liver and muscle glycogen } \\
\text { storage; } \\
\text { Regulates body hormone. }\end{array}$ & {$[32,61,65,81]$} \\
\hline Tremellaceae & Tremella fuciformis & $\begin{array}{l}\alpha \text { - }(1 \rightarrow 3) \text {-linked } \mathrm{D} \text {-mannan } \\
\text { as backbone chain and small } \\
\text { xylose- and glucuronic } \\
\text { acid-containing side chains }\end{array}$ & $\begin{array}{l}\text { Improves muscular function; } \\
\text { Promotes antioxidant enzyme activity } \\
\text { and strong free radical scavenging } \\
\text { activity; } \\
\text { Promotes liver protein synthesis. }\end{array}$ & {$[48,50,64,73]$} \\
\hline Marasmiaceae & Lentinus edodes & $\begin{array}{c}\text { Mannose, glucose, and } \\
\text { galactose }\end{array}$ & $\begin{array}{l}\text { Strong free radical scavenging activity; } \\
\text { Promotes antioxidant enzyme activity. }\end{array}$ & {$[49,74]$} \\
\hline Physalacriaceae & Armillaria ostoyae & $\begin{array}{c}\text { Glucan and branched } \\
\text { galactoglucan with glucose } \\
\text { and galactose at the molar } \\
\text { ratio of } 6: 1\end{array}$ & Antioxidant activity. & {$[75]$} \\
\hline Physalacriaceae & Flammulina velutipes & $\begin{array}{c}\text { Three heteropolysaccharides } \\
\text { with glucose, galactose, } \\
\text { mannose, and xylose at } \\
\text { different molar ratios and } \\
\text { Mw of } 9,930,62,290 \text {, and } \\
36,310 \mathrm{Da} \\
\end{array}$ & Antioxidant activity. & {$[76]$} \\
\hline Polyporaceae & Lentinus fusipes & $\begin{array}{l}\text { Heteroglycan with } \\
\text { D-galactose and } \mathrm{D} \text {-glucose } \\
\text { in the molar ratio of } \\
\text { approximately } 1: 1 \text { and } \mathrm{Mw} \text { of } \\
60 \mathrm{kDa}\end{array}$ & $\begin{array}{l}\text { Stimulates splenocyte and macrophage } \\
\text { activity; } \\
\text { DPPH radical scavenging activity. }\end{array}$ & [77] \\
\hline Polyporaceae & Ganoderma atrum & $\begin{array}{c}\text { Polysaccharide- } \\
\text { phenolic/protein conjugates } \\
\text { with polysaccharide } \\
\text { comprising mannose, } \\
\text { galactose, and glucose in the } \\
\text { ratio of } 1: 1.28: 4.91 \text { and } \mathrm{Mw} \\
\text { of } 1,013 \mathrm{kDa}\end{array}$ & $\begin{array}{l}\text { Antioxidant activity; } \\
\text { Improves immunomodulation. }\end{array}$ & {$[78,79]$} \\
\hline Pleurotaceae & Pleurotus abalones & $\begin{array}{l}\text { Polysaccharide- } \\
\text { peptide complex with } \\
\text { polysaccharide comprising } \\
\text { glucose, rhamnose, } \\
\text { glucuronic acid, and } \\
\text { galactose in the molar ratio } \\
\text { of } 22.4: 1: 1.7: 1.6 \text { and } \\
\text { peptide having N-terminal } \\
\text { amino acid sequence }\end{array}$ & Antioxidant activity. & [80] \\
\hline
\end{tabular}


TABLE 4: Other bioactive constituents (than polysaccharides) and possible antifatigue mechanisms of some important mushrooms.

\begin{tabular}{|c|c|c|c|c|}
\hline Family & Species & Active components & Mechanism for antifatigue & Ref. \\
\hline \multirow[t]{3}{*}{ Cordycipitaceae } & \multirow[t]{3}{*}{ Cordyceps sinensis } & Polypeptide & $\begin{array}{l}\text { Improves cardiovascular function through } \\
\text { vasodilation effect; } \\
\text { Improves energy state of liver. }\end{array}$ & [53] \\
\hline & & Mannitol & Free radical scavenging activity. & {$[82]$} \\
\hline & & Cordycepin & Free radical scavenging activity. & [83] \\
\hline \multirow{4}{*}{ Ganodermataceae } & \multirow{4}{*}{$\begin{array}{l}\text { Ganoderma } \\
\text { lucidum }\end{array}$} & Protein of LZ-8 & $\begin{array}{l}\text { Improves T lymphocytes response to } \\
\text { cytokines; }\end{array}$ & $\overline{[84]}$ \\
\hline & & $\begin{array}{l}\text { Peptide with amino acids rich in } \\
\text { phenylalanine, aspartic acid, proline, } \\
\text { histidine, and isoleucine }\end{array}$ & Antioxidant activity. & {$[11]$} \\
\hline & & Triterpenoids & $\begin{array}{l}\text { Strong antioxidant activity; } \\
\text { Regulates body testosterone level. }\end{array}$ & {$[62,85]$} \\
\hline & & Adenosine & $\begin{array}{l}\text { Inhibitory platelet aggregation to enhance } \\
\text { blood circulation. }\end{array}$ & {$[86]$} \\
\hline Agaricaceae & Agaricus bisporus & $\begin{array}{l}\text { Gallic acid, flavonoid, ascorbic acid, and } \\
\text { phenolic compounds }\end{array}$ & Antioxidant activity. & {$[87,88]$} \\
\hline Tricholomataceae & $\begin{array}{l}\text { Tricholoma } \\
\text { matsutake }\end{array}$ & Peptide & $\begin{array}{c}\text { Improves cardiovascular function by } \\
\text { antihypertensive action; } \\
\text { Free radical scavenging activity. }\end{array}$ & [89] \\
\hline Meripilaceae & Grifola gargal & Adenosine & $\begin{array}{l}\text { Promotes glucose uptake in skeletal muscle } \\
\text { cells. }\end{array}$ & [90] \\
\hline Fomitopsidaceae & $\begin{array}{c}\text { Antrodia } \\
\text { cinnamomea }\end{array}$ & $\begin{array}{c}\text { Ergostane and lanostane skeleton } \\
\text { triterpenoids }\end{array}$ & Significantly improves muscular function. & {$[12]$} \\
\hline Hymenochaetaceae & Inonotus obliquus & $\begin{array}{l}\text { Polyphenol of inonoblins and } \\
\text { phelligridins }\end{array}$ & $\begin{array}{c}\text { Significant DPPH radical scavenging and } \\
\text { moderate superoxide anion scavenging } \\
\text { activities. }\end{array}$ & {$[44]$} \\
\hline
\end{tabular}

Besides the above-mentioned components, the mannitol and cordycepin in $C$. sinensis extracts were also found active for the scavenging of free radicals. Mannitol is a kind of sugar alcohol that commonly exists in bacteria, yeast, and mushrooms. It acted as a ROS quencher scavenging hydroxyl radicals generated by the pathogen defense system [82]. Cordycepin is a 3-deoxyadenosine which is the derivative of nucleoside adenosine with absence of oxygen in the $3^{\prime}$ position of its ribose. It also showed scavenging ability of free radicals like hydroxyl radicals and superoxide anion [83].

All the effects of those bioactive components from edible and medicinal mushrooms will help to regulate body balance and ensure a well-functioned body system to reduce the occurrence of fatigue. Table 4 summarizes the active components of typical edible and medicinal mushrooms in Section 5 and their corresponding functions in fatigue mitigation. Figure 3 further lists typical structures of active biological components in edible and medicinal mushrooms, including $\beta$-1,3-glucan, adenosine, triterpenoid, and polyphenol.

\section{Concluding Remarks and Future Perspectives}

There are four major actual sites of action for the antifatigue activities of edible and medicinal mushrooms, namely, the muscular system, body antioxidant system, cardiovascular system, hormone system, and immune system. For the muscular function, the mushrooms mainly affect liver and muscle glycogen storage and blood lactic acid, which are the major causes for muscular fatigue. For the antioxidant effect, the mushrooms enhance the body antioxidant system by stimulating enzymes such as SOD and GSH-Px as well as limiting the detrimental effect of ROS. For the immune and hormone systems, the antifatigue function is achieved by stimulating the activities of immune cells and the expression of cytokines, as well as the testosterone. Besides these major antifatigue effects, some specific medicinal effects of edible and medicinal mushrooms also help to avoid fatigue, through improvement of liver energy state and function, blood circulation, and blood glucose regulation. Overall these demonstrate that edible and medicinal mushrooms can promote the proper function and balance of the biological systems to maintain the basic harmonious pattern of body for antifatigue.

Among the various bioactive components found in edible and medicinal mushrooms, polysaccharides are the most common active components responsible for their activities, with their activities differing based on size, structure, and composition. In addition, some other specific bioactive components, such as peptides, adenosines, triterpenoids, polyphenols, and flavonoids, can also improve body functions through action on the antioxidant, cardiovascular, hormone, and immune systems.

Because most experiments have been carried out in animal models, the results are not all convincing to prove that 
edible and medicinal mushrooms can effectively deal with human fatigue. Meanwhile, other than polysaccharides, there are few results about the direct correlation of one specific bioactive component with the antifatigue effect, especially from the evaluation of muscular function improvement. Further studies should be performed on these aspects for better understanding of the mechanism for the antifatigue function of edible and medicinal mushrooms.

\section{Conflicts of Interest}

No potential conflicts of interest were reported by the authors.

\section{Acknowledgments}

This work was financially supported by Shenzhen Basic Research Project (JCYJ20160531184200806), the Science Technology Planning Project of Guangdong Province (2016A050503017), and the Hong Kong Polytechnic University.

\section{References}

[1] M. Tanaka, Y. Baba, Y. Kataoka et al., "Effects of (-)-epigallocatechin gallate in liver of an animal model of combined (physical and mental) fatigue," Nutrition, vol. 24, no. 6, pp. 599603, 2008.

[2] R. H. Fitts, "Cellular mechanisms of muscle fatigue," Physiological Reviews, vol. 74, no. 1, pp. 49-94, 1994.

[3] Q. Li, Y. Wang, G. Cai et al., "Antifatigue activity of liquid cultured Tricholoma matsutake mycelium partially via regulation of antioxidant pathway in mouse," BioMed Research International, vol. 2015, Article ID 562345, 10 pages, 2015.

[4] L. Barros, P. Baptista, L. M. Estevinho, and I. C. F. R. Ferreira, "Bioactive properties of the medicinal mushroom Leucopaxillus giganteus mycelium obtained in the presence of different nitrogen sources," Food Chemistry, vol. 105, no. 1, pp. 179-186, 2007.

[5] C. Sarikurkcu, B. Tepe, and M. Yamac, "Evaluation of the antioxidant activity of four edible mushrooms from the Central Anatolia, Eskisehir-Turkey: Lactarius deterrimus, Suillus collitinus, Boletus edulis, Xerocomus chrysenteron," Bioresource Technology, vol. 99, no. 14, pp. 6651-6655, 2008.

[6] Z. Wang, D. Luo, and Z. Liang, "Structure of polysaccharides from the fruiting body of Hericium erinaceus Pers," Carbohydrate Polymers, vol. 57, no. 3, pp. 241-247, 2004.

[7] H. G. Kim, D. H. Yoon, W. H. Lee et al., "Phellinus linteus inhibits inflammatory mediators by suppressing redox-based NF- $\kappa$ B and MAPKs activation in lipopolysaccharide-induced RAW 264.7 macrophage," Journal of Ethnopharmacology, vol. 114, no. 3, pp. 307-315, 2007.

[8] A. Synytsya, K. Mícková, I. Jablonský et al., "Glucans from fruit bodies of cultivated mushrooms Pleurotus ostreatus and Pleurotus eryngii: structure and potential prebiotic activity," Carbohydrate Polymers, vol. 76, no. 4, pp. 548-556, 2009.

[9] S. P. Wasser, "Current findings, future trends, and unsolved problems in studies of medicinal mushrooms," Applied Microbiology and Biotechnology, vol. 89, no. 5, pp. 1323-1332, 2011.

[10] U. Lindequist, T. H. G. Niedermeyer, and W.-D. Jülich, "The pharmacological potential of mushrooms," Evidence-Based
Complementary and Alternative Medicine, vol. 2, no. 3, pp. 285299, 2005.

[11] V. U. Girjal, S. Neelagund, and M. Krishnappa, "Antioxidant properties of the peptides isolated from ganoderma lucidum fruiting body," International Journal of Peptide Research and Therapeutics, vol. 18, no. 4, pp. 319-325, 2012.

[12] C.-C. Huang, M.-C. Hsu, W.-C. Huang, H.-R. Yang, and C.C. Hou, "Triterpenoid-rich extract from antrodia camphorata improves physical fatigue and exercise performance in mice," Evidence-Based Complementary and Alternative Medicine, vol. 2012, Article ID 364741, 8 pages, 2012.

[13] Y. Yoshioka, E. Harada, D. Ge et al., "Adenosine isolated from Grifola gargal promotes glucose uptake via PI3K and AMPK signalling pathways in skeletal muscle cells," Journal of Functional Foods, vol. 33, pp. 268-277, 2017.

[14] T. Islam, X. Yu, and $\mathrm{B} . \mathrm{Xu}$, "Phenolic profiles, antioxidant capacities and metal chelating ability of edible mushrooms commonly consumed in China," LWT - Food Science and Technology, vol. 72, pp. 423-431, 2016.

[15] J. M. Grau, J. Casademont, E. Pedrol, J. Fernandez-Sola, F. Cardellach, and N. A. Barros Urbano-Marquez, "Chronic fatigue syndrome: studies on skeletal muscle," Clinical Neuropathology, vol. 11, no. 6, pp. 329-332, 1992.

[16] B. Rattray, C. Argus, K. Martin, J. Northey, and M. Driller, "Is it time to turn our attention toward central mechanisms for postexertional recovery strategies and performance?" Frontiers in Physiology, vol. 6, article 79, 2015.

[17] L. Nybo, "CNS fatigue and prolonged exercise: effect of glucose supplementation," Medicine and Science in Sports and Exercise, vol. 35, no. 4, pp. 589-594, 2003.

[18] W. J. Evans and C. P. Lambert, "Physiological basis of fatigue," American Journal of Physical Medicine \& Rehabilitation, vol. 86, no. 1, pp. S29-S46, 2007.

[19] L. J. You, M. M. Zhao, J. M. Regenstein, and J. Y. Ren, "In vitro antioxidant activity and in vivo anti-fatigue effect of loach (Misgurnus anguillicaudatus) peptides prepared by papain digestion," Food Chemistry, vol. 124, no. 1, pp. 188-194, 2011.

[20] J. Bergström, L. Hermansen, E. Hultman, and B. Saltin, "Diet, muscle glycogen and physical performance," Acta Physiologica Scandinavica, vol. 71, no. 2-3, pp. 140-150, 1967.

[21] L. Wang, H.-L. Zhang, R. Lu et al., “The decapeptide CMS001 enhances swimming endurance in mice," Peptides, vol. 29, no. 7, pp. 1176-1182, 2008.

[22] J. Zoll, H. Sanchez, B. N'Guessan et al., "Physical activity changes the regulation of mitochondrial respiration in human skeletal muscle," Journal of Physiology, vol. 543, no. 1, pp. 191200, 2002.

[23] J. P. Ribeiro, V. Hughes, R. A. Fielding, W. Holden, W. Evans, and H. G. Knuttgen, "Metabolic and ventilatory responses to steady state exercise relative to lactate thresholds," European Journal of Applied Physiology and Occupational Physiology, vol. 55, no. 2, pp. 215-221, 1986.

[24] B. Ekblom, "Factors determining maximal aerobic power," Acta Physiologica Scandinavica, vol. 128, no. 556, pp. 15-19, 1986.

[25] B. Lamou, G. S. Taiwe, A. Hamadou et al., "Antioxidant and antifatigue properties of the aqueous extract of Moringa oleifera in rats subjected to forced swimming endurance test," Oxidative Medicine and Cellular Longevity, vol. 2016, Article ID 3517824, 9 pages, 2016.

[26] N. Belluardo, H. Westerblad, G. Mudó et al., "Neuromuscular junction disassembly and muscle fatigue in mice lacking 
neurotrophin-4," Molecular and Cellular Neuroscience, vol. 18, no. 1, pp. 56-67, 2001.

[27] K. Jung, I.-H. Kim, and D. Han, "Effect of medicinal plant extracts on forced swimming capacity in mice," Journal of Ethnopharmacology, vol. 93, no. 1, pp. 75-81, 2004.

[28] B. Yu, Z.-X. Lu, X.-M. Bie, F.-X. Lu, and X.-Q. Huang, "Scavenging and anti-fatigue activity of fermented defatted soybean peptides," European Food Research and Technology, vol. 226, no. 3, pp. 415-421, 2008.

[29] J. Song, Y. Wang, M. Teng et al., "Studies on the antifatigue activities of Cordyceps militaris fruit body extract in mouse model," Evidence-based Complementary and Alternative Medicine, vol. 2015, Article ID 174616, 2015.

[30] S.-H. Suh, I.-Y. Paik, and K. A. Jacobs, "Regulation of blood glucose homeostasis during prolonged exercise," Molecules and Cells, vol. 23, no. 3, pp. 272-279, 2007.

[31] S.-Y. Lin, J.-B. Liu, and S. Cheng, "Experimental study of antifatigue on the functional liquid of chinese traditional medicine," Food Science, vol. 26, pp. 224-226, 2005.

[32] T. Li and W. Li, "Impact of polysaccharides from Cordyceps on anti-fatigue in mice," Scientific Research and Essays, vol. 4, no. 7, pp. 705-709, 2009.

[33] W. Wei, L. Zheng, M. Yu, N. Jiang, Z. Yang, and X. Luo, "Antifatigue activity of extract form the submerged fermentation of Ganoderma Lucidum using Radix astragali as substrate," Journal of Animal and Plant Sciences (JAPS), vol. 6, no. 3, pp. 677-684, 2010.

[34] C. Tsopanakis and A. Tsopanakis, "Stress hormonal factors, fatigue, and antioxidant responses to prolonged speed driving," Pharmacology Biochemistry and Behavior, vol. 60, no. 3, pp. 747751, 1998.

[35] J. R. Liang, X. C. Zhang, Z. S. Liu, and Q. S. Liu, "Effect of food and medicine fungi on anti-fatigue in mice," Chinese Agricultural Science Bulletin, vol. 20, no. 1, pp. 135-137, 2004.

[36] L.-Y. Wu, M.-F. Wu, H.-F. Lu et al., "Evaluation of hirsutella sinensis mycelium for antifatigue effect," In Vivo, vol. 29, no. 2, pp. 263-267, 2015.

[37] J.-Y. Wu, H.-P. Leung, W.-Q. Wang, and C.-P. Xu, "Mycelial fermentation characteristics and anti-fatigue activities of a Chinese caterpillar fungus, ophiocordyceps sinensis strain Cs-HK1 (Ascomycetes)," International Journal of Medicinal Mushrooms, vol. 16, no. 2, pp. 105-114, 2014.

[38] C.-L. Wang, L. Zhang, Y.-G. Zu, and Y. Huang, "Study on the anti-fatigue effect of water extract from agaricus bisporus," Science and Technology of Food Industry, vol. 32, no. 5, article 417, pp. 379-380, 2011.

[39] R. Kumar, P. S. Negi, B. Singh, G. Ilavazhagan, K. Bhargava, and N. K. Sethy, "Cordyceps sinensis promotes exercise endurance capacity of rats by activating skeletal muscle metabolic regulators," Journal of Ethnopharmacology, vol. 136, no. 1, pp. 260-266, 2011.

[40] D. G. Hardie and K. Sakamoto, "AMPK: a key sensor of fuel and energy status in skeletal muscle," Physiology, vol. 21, no. 1, pp. 48-60, 2006.

[41] J. Lin, H. Wu, P. T. Tarr et al., "Transcriptional co-activator PGC- $1 \alpha$ drives the formation of slow-twitch muscle fibres," Nature, vol. 418, no. 6899, pp. 797-801, 2002.

[42] Y. X. Wang, C. L. Zhang, R. T. Yu et al., "Regulation of muscle fiber type and running endurance by PPAR $\delta$," PLoS Biology, vol. 2, no. 10, article e294, 2004.
[43] J.-H. Seo, Y.-H. Sung, K.-J. Kim, M.-S. Shin, E.-K. Lee, and C.-J. Kim, "Effects of Phellinus linteus administration on serotonin synthesis in the brain and expression of monocarboxylate transporters in the muscle during exhaustive exercise in rats," Journal of Nutritional Science and Vitaminology, vol. 57, no. 1, pp. 95-103, 2011.

[44] I.-K. Lee, Y.-S. Kim, Y.-W. Jang, J.-Y. Jung, and B.-S. Yun, "New antioxidant polyphenols from the medicinal mushroom Inonotus obliquus," Bioorganic and Medicinal Chemistry Letters, vol. 17, no. 24, pp. 6678-6681, 2007.

[45] J. S. Beckman, T. W. Beckman, J. Chen, P. A. Marshall, and B. A. Freeman, "Apparent hydroxyl radical production by peroxynitrite: implications for endothelial injury from nitric oxide and superoxide," Proceedings of the National Academy of Sciences of the United States of America, vol. 87, no. 4, pp. 1620-1624, 1990.

[46] C.-H. Dong and Y.-J. Yao, "In vitro evaluation of antioxidant activities of aqueous extracts from natural and cultured mycelia of Cordyceps sinensis," LWT - Food Science and Technology, vol. 41, no. 4, pp. 669-677, 2008.

[47] S. Joseph, B. Sabulal, V. George, T. P. Smina, and K. K. Janardhanan, "Antioxidative and antiinflammatory activities of the chloroform extract of Ganoderma lucidum found in South India," Scientia Pharmaceutica, vol. 77, no. 1, pp. 111-121, 2009.

[48] B. Chen, "Optimization of extraction of Tremella fuciformis polysaccharides and its antioxidant and antitumour activities in vitro," Carbohydrate Polymers, vol. 81, no. 2, pp. 420-424, 2010.

[49] Z. Yu, Y. LiHua, Y. Qian, and L. Yan, "Effect of Lentinus edodes polysaccharide on oxidative stress, immunity activity and oral ulceration of rats stimulated by phenol," Carbohydrate Polymers, vol. 75, no. 1, pp. 115-118, 2009.

[50] S. Y. Ma, L. He, and L. F. Yao, "Research advances on structural characteristics and bioactivity of T. fuciformis polysaccharides," Food Science, vol. 31, no. 23, pp. 411-416, 2010.

[51] J.-M. Savoie, N. Minvielle, and M. L. Largeteau, "Radicalscavenging properties of extracts from the white button mushroom, Agaricus bisporus," Journal of the Science of Food and Agriculture, vol. 88, no. 6, pp. 970-975, 2008.

[52] R. E. Klabunde, Cardiovascular Physiology Concepts, Lippincott Williams \& Wilkins, Philadelphia, Pa, USA, 2011.

[53] M. G. Feng, Q. G. Zhou, and G. H. Feng, "Vasodilating effect of cultured Cordyceps sinensis (Berk) Sacc. mycelia in anesthetized dogs," Zhong Yao Tong Bao, vol. 12, no. 12, pp. 41-60, 1987.

[54] A. S. Most, N. A. Ruocco Jr., and H. Gewirtz, "Effect of a reduction in blood viscosity on maximal myocardial oxygen delivery distal to a moderate coronary stenosis," Circulation, vol. 74, no. 5, pp. 1085-1092, 1986.

[55] S.-Y. Wang, M.-L. Hsu, H.-C. Hsu et al., "The anti-tumor effect of Ganoderma lucidum is mediated by cytokines released from activated macrophages and T lymphocytes," International Journal of Cancer, vol. 70, no. 6, pp. 699-705, 1997.

[56] T. Jia and B. H. S. Lau, "The immuno-enhancing effect of Chinese herbal medicine Cordyceps sinensis on macrophage J774," Zhongguo Yao Xue Za Zhi (Zhongguo Yao Xue Hui: 1989), vol. 32, no. 3, pp. 142-144, 1997.

[57] G. Z. Chen, G. L. Chen, and C. M. Tong, "Effect of alcoholic extract C. sinensis on T-lymphocyte subsets," Journal of Central South University (Medical Science, vol. 12, no. 4, pp. 311-314, 1987.

[58] T. Mao, J. Van De Water, C. L. Keen, J. S. Stern, R. Hackman, and M. E. Gershwin, "Two mushrooms, Grifola frondosa and Ganoderma lucidum, can stimulate cytokine gene expression and 
proliferation in human T lymphocytes," International Journal of Immunotherapy, vol. 15, no. 1, pp. 13-22, 1999.

[59] D. Wu, M. Pae, Z. Ren, Z. Guo, D. Smith, and S. N. Meydani, "Dietary supplementation with white button mushroom enhances natural killer cell activity in C57BL/6 mice," Journal of Nutrition, vol. 137, no. 6, pp. 1472-1477, 2007.

[60] A. Morgentaler, Testosterone for Life: Recharge Your Vitality, Sex Drive, Muscle Mass, and Overall Health, McGraw-Hill Professional, New York, NY, USA, 2008.

[61] B.-M. Huang, C.-C. Hsu, S.-J. Tsai, C.-C. Sheu, and S.-F. Leu, "Effects of Cordyceps sinensis on testosterone production in normal mouse Leydig cells," Life Sciences, vol. 69, no. 22, pp. 2593-2602, 2001.

[62] J. Liu, K. Shimizu, F. Konishi et al., "Anti-androgenic activities of the triterpenoids fraction of Ganoderma lucidum," Food Chemistry, vol. 100, no. 4, pp. 1691-1696, 2007.

[63] N. Manabe, M. Sugimoto, Y. Azuma et al., "Effects of the mycelial extract of cultured Cordyceps sinensis on in vivo hepatic energy metabolism in the mouse," Japanese Journal of Pharmacology, vol. 70, no. 1, pp. 85-88, 1996.

[64] Y. Wei and C. Zheng, "Effects of Tremella polysaccharides on synthesis of protein and on glycogen content in normal and injured livers of mice," Acta Pharmacologica Sinica, vol. 7, no. 4, pp. 364-367, 1986.

[65] S. P. Li, G. H. Zhang, Q. Zeng et al., "Hypoglycemic activity of polysaccharide, with antioxidation, isolated from cultured Cordyceps mycelia," Phytomedicine, vol. 13, no. 6, pp. 428-433, 2006.

[66] T. Kiho, A. Yamane, J. Hui, S. Usui, and S. Ukai, "Polysaccharides in fungi. XXXVI.1 Hypoglycemic activity of a polysaccharide (CS-F30) from the cultural mycelium of Cordyceps sinensis and its effect on glucose metabolism in mouse liver," Biological and Pharmaceutical Bulletin, vol. 19, no. 2, pp. 294-296, 1996.

[67] T. Kiho, H. Morimoto, T. Kobayashi et al., "Effect of a polysaccharide (TAP) from the fruiting bodies of Tremella aurantia on glucose metabolism in mouse liver," Bioscience, Biotechnology and Biochemistry, vol. 64, no. 2, pp. 417-419, 2000.

[68] S. P. Wasser, "Medicinal mushrooms as a source of antitumor and immunomodulating polysaccharides," Applied Microbiology and Biotechnology, vol. 60, no. 3, pp. 258-274, 2002.

[69] Z. Zhonghui, Z. Xiaowei, and F. Fang, "Ganoderma lucidum polysaccharides supplementation attenuates exercise-induced oxidative stress in skeletal muscle of mice," Saudi Journal of Biological Sciences, vol. 21, no. 2, pp. 119-123, 2014.

[70] M. Bobovčák, R. Kuniaková, J. Gabriž, and J. Majtán, “Effect of pleuran ( $\beta$-glucan from pleurotus ostreatus) supplementation on cellular immune response after intensive exercise in elite athletes," Applied Physiology, Nutrition and Metabolism, vol. 35, no. 6, pp. 755-762, 2010.

[71] P. Maity, A. K. Nandi, D. K. Manna et al., "Structural characterization and antioxidant activity of a glucan from Meripilus giganteus," Carbohydrate Polymers, vol. 157, pp. 1237-1245, 2017.

[72] P. Maity, I. K. Sen, P. K. Maji et al., "Structural, immunological, and antioxidant studies of $\beta$-glucan from edible mushroom Entoloma lividoalbum," Carbohydrate Polymers, vol. 123, pp. 350-358, 2015.

[73] X. L. Xin, Y. L. Shi, and L. H. Yang, "Effects of tremella polysaccharide on isolated skeletal muscular fatigue," Acta Agriculturae Boreali-Occidentalis Sinica, vol. 2, article 133, pp. 128-130, 2006.
[74] Y. G. Zhong, N. Lin, S. Wang, and C. Liu, "Study on antioxidative and antimicrobial activities of Lentinan," Food Science and Technology, vol. 7, 2007.

[75] K.-C. Siu, L. Xu, X. Chen, and J.-Y. Wu, "Molecular properties and antioxidant activities of polysaccharides isolated from alkaline extract of wild Armillaria ostoyae mushrooms," Carbohydrate Polymers, vol. 137, pp. 739-746, 2016.

[76] Y. Liu, B. Zhang, S. A. Ibrahim, S.-S. Gao, H. Yang, and W. Huang, "Purification, characterization and antioxidant activity of polysaccharides from Flammulina velutipes residue," Carbohydrate Polymers, vol. 145, pp. 71-77, 2016.

[77] D. K. Manna, P. Maity, A. K. Nandi et al., "Structural elucidation and immunostimulating property of a novel polysaccharide extracted from an edible mushroom Lentinus fusipes," Carbohydrate Polymers, vol. 157, pp. 1657-1665, 2017.

[78] H. Zhang, S. W. Cui, S.-P. Nie, Y. Chen, Y.-X. Wang, and M.-Y. Xie, "Identification of pivotal components on the antioxidant activity of polysaccharide extract from Ganoderma atrum," Bioactive Carbohydrates and Dietary Fibre, vol. 7, no. 2, pp. 918, 2016.

[79] Y. Chen, M.-Y. Xie, S.-P. Nie, C. Li, and Y.-X. Wang, "Purification, composition analysis and antioxidant activity of a polysaccharide from the fruiting bodies of Ganoderma atrum," Food Chemistry, vol. 107, no. 1, pp. 231-241, 2008.

[80] N. Li, L. Li, J. C. Fang et al., "Isolation and identification of a novel polysaccharide-peptide complex with antioxidant, antiproliferative and hypoglycaemic activities from the abalone mushroom," Bioscience Reports, vol. 32, no. 3, pp. 221-228, 2012.

[81] J.-Y. Wu, X. Chen, and K.-C. Siu, "Isolation and structure characterization of an antioxidative glycopeptide from mycelial culture broth of a medicinal fungus," International Journal of Molecular Sciences, vol. 15, no. 10, pp. 17318-17332, 2014.

[82] D. B. Jennings, M. Ehrenshaft, D. Mason Pharr, and J. D. Williamson, "Roles for mannitol and mannitol dehydrogenase in active oxygen-mediated plant defense," Proceedings of the National Academy of Sciences of the United States of America, vol. 95, no. 25, pp. 15129-15133, 1998.

[83] X. Q. Zhang, Y. P. Pu, L. H. Yin, and W. J. Zhong, "Study on the scavenging effect on superoxide anion free radical and hydroxyl free radical of cordycep sinensis and mycelium of cultured cordyceps sinensis," Chinese Journal of Gerontology, vol. 11, pp. 773-775, 2003.

[84] M. Haak-Frendscho, K. Kino, T. Sone, and P. Jardieu, "Ling Zhi-8: a novel T cell mitogen induces cytokine production and upregulation of ICAM-1 Expression," Cellular Immunology, vol. 150, no. 1, pp. 101-113, 1993.

[85] M. Zhu, Q. Chang, L. K. Wong, F. S. Chong, and R. C. Li, "Triterpene antioxidants from Ganoderma lucidum," Phytotherapy Research, vol. 13, no. 6, pp. 529-531, 1999.

[86] H. Kawagishi, F. Fukuhara, M. Sazuka, A. Kawashima, T. Mitsubori, and T. Tomita, " 5 '-deoxy-5' -methylsulphinyladenosine, a platelet aggregation inhibitor from Ganoderma lucidum," Phytochemistry, vol. 32, no. 2, pp. 239-241, 1993.

[87] N. Sugihara, T. Arakawa, M. Ohnishi, and K. Furuno, "Antiand pro-oxidative effects of flavonoids on metal-induced lipid hydroperoxide-dependent lipid peroxidation in cultured hepatocytes loaded with $\alpha$-linolenic acid," Free Radical Biology and Medicine, vol. 27, no. 11-12, pp. 1313-1323, 1999.

[88] N. Salah, N. J. Miller, G. Paganga, L. Tijburg, G. P. Bolwell, and C. Rice-Evans, "Polyphenolic flavanols as scavengers of aqueous phase radicals and as chain-breaking antioxidants," Archives of Biochemistry and Biophysics, vol. 322, no. 2, pp. 339-346, 1995. 
[89] X. Geng, G. Tian, W. Zhang et al., "A tricholoma matsutake peptide with angiotensin converting enzyme inhibitory and antioxidative activities and antihypertensive effects in spontaneously hypertensive rats," Scientific Reports, vol. 6, Article ID 24130, 2016.

[90] R. M. Berne, "The role of adenosine in the regulation of coronary blood flow," Circulation Research, vol. 47, no. 6, pp. 807-813, 1980.

[91] P. Sa-ard, R. Sarnthima, S. Khammuang, and W. Kanchanarach, "Antioxidant, antibacterial and DNA protective activities of protein extracts from Ganoderma lucidum," Journal of Food Science and Technology, vol. 52, no. 5, pp. 2966-2973, 2014. 

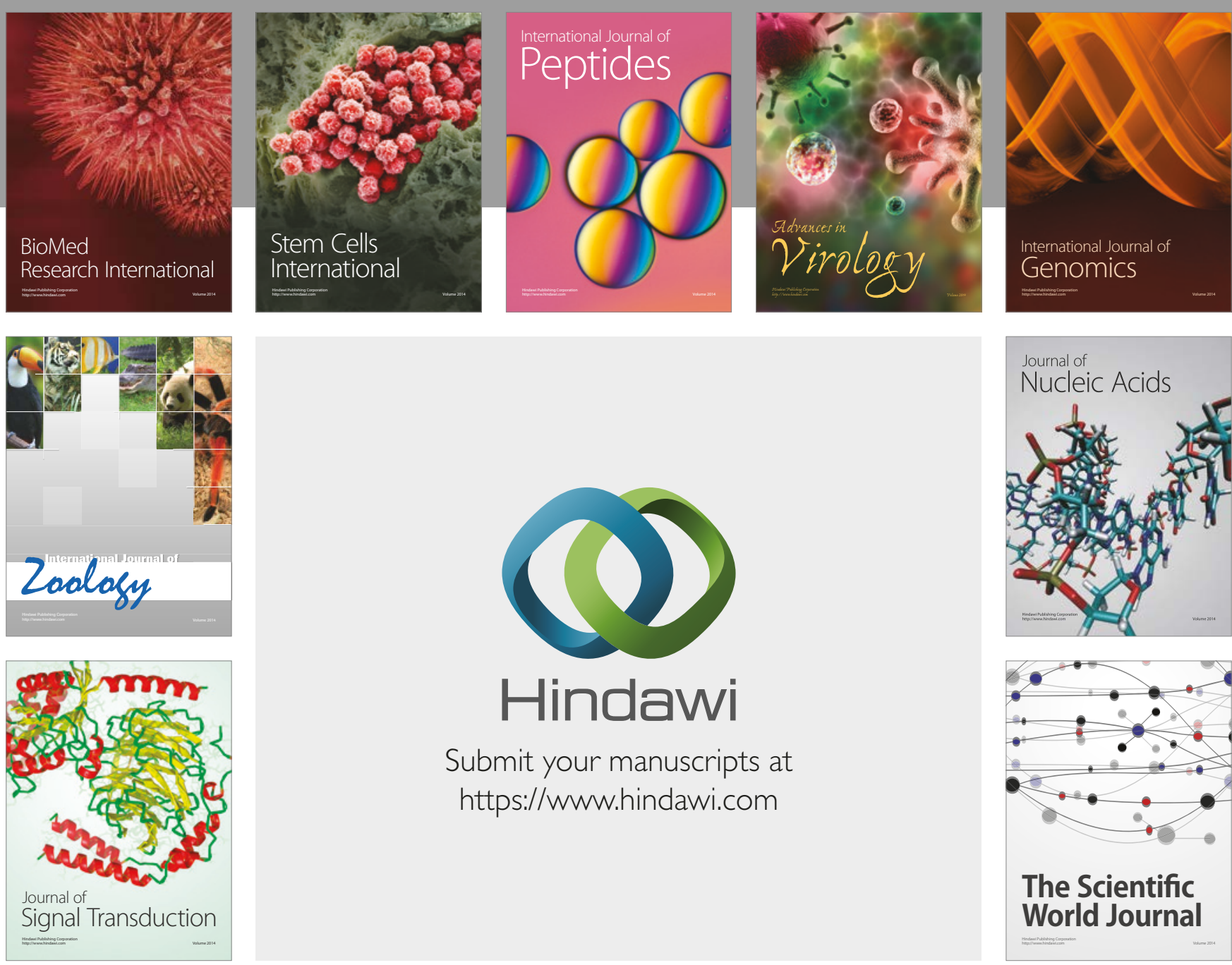

Submit your manuscripts at

https://www.hindawi.com
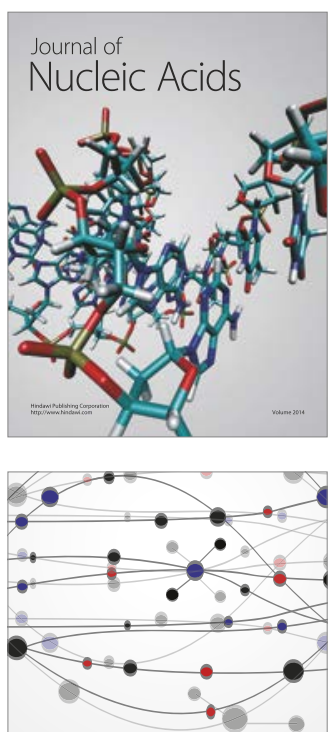

The Scientific World Journal

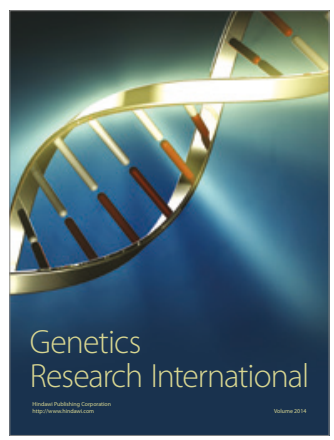

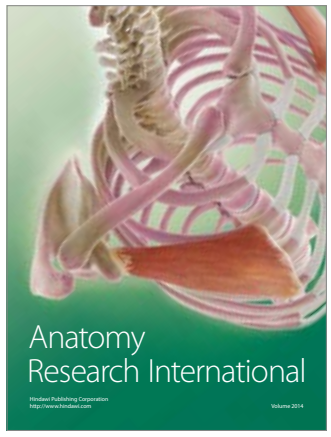

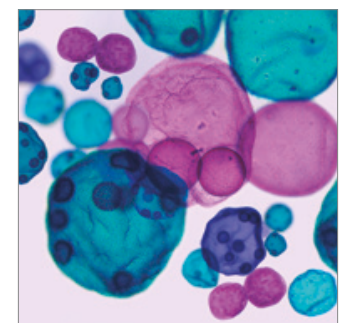

International Journal of Microbiology
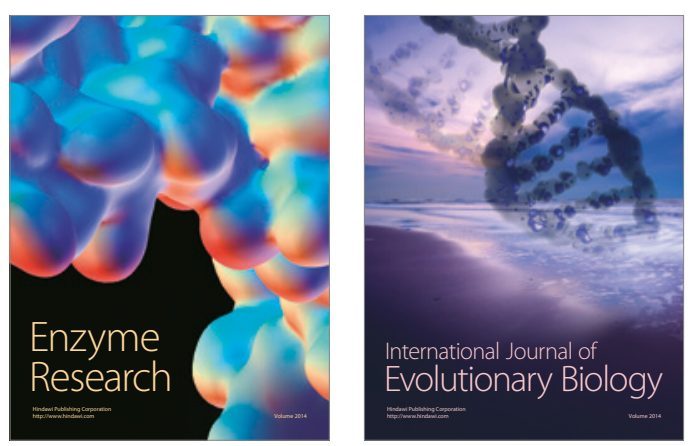
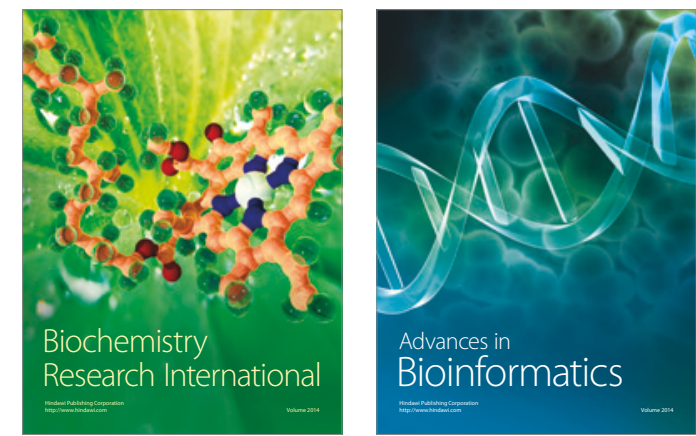

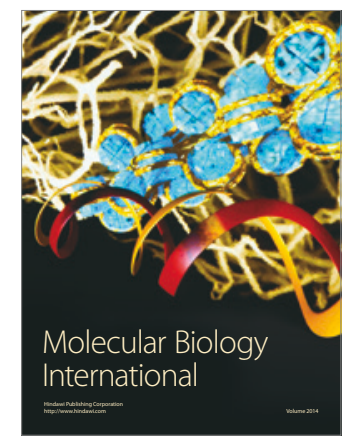

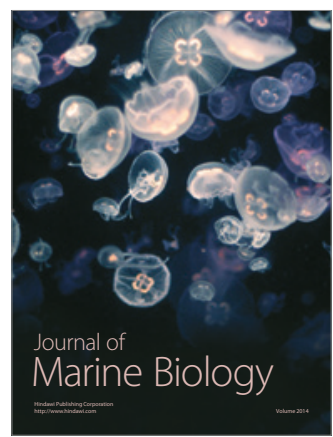

